\title{
A novel porcine bocavirus harbors a variant NP gene
}

\author{
Sung $\mathrm{J} \mathrm{Yoo}^{1}$, Sun Young Sunwoo ${ }^{1,2}$, Seong Sik Ko ${ }^{1}$, Sang H Je' ${ }^{1}$, Dong Uk Lee ${ }^{1}$ and Young S Lyoo ${ }^{1 *}$
}

\begin{abstract}
Background: Porcine bocavirus is classified within the genus Bocaparvovirus, family Parvoviridae. Unlike other parvoviruses, the members of genus Bocaparvovirus (bocaparvoviruses) encode an additional open reading frame (NP1). Many strains of PBoVs have been identified in domestic pigs and recognized as a potential emerging pathogen causing respiratory and gastrointestinal disease.

Findings: A new strain of porcine bocavirus (PBoV) that harbored the shortest NP1 gene among all currently characterized PBoVs (provisionally named as 'PBoV-KU14') was detected in domestic pigs. Almost the complete genome sequence was obtained, approximately 4,630 nucleotides in lengths with putative NS1, NP1, and VP1/2 genes of $1,908,600,1,851$ bp, respectively. Phylogenetic and comparative analysis was performed using protein and nucleotide sequences. It was revealed that PBoV-KU14 belongs to the genus Bocaparvovirus and species Ungulate bocaparvovirus 4. However, phylogenetic incongruence was observed among species classifications based on the NS1, NP1 and VP1/2 proteins, which indicates a probability of crossover recombination. Conserved protein domains unique for genus Bocaparvovirus in NP1, VP1 protein were also detected.
\end{abstract}

Conclusion: NP1 gene truncation supposed to be caused by cross over recombination was detected in a new strain of PBoV (PBoV-KU14). Considering high rates of substitution and recombination in parvovirus, periodic surveillance study to monitor genomic variation and find new strainsof PBoVs seems to be needed.

Keywords: Porcine bocavirus, Phylogenetic incongruence, NP1 gene truncation, Recombination, Surveillance

The family parvoviridae is divided into two subfamilies according to the range of infecting host such as parvovirinae (infecting vertebrae) and densovirinae (infecting arthropods). The subfamily Parvovirinae is subdivided into eight genera, Amdoparvovirus, Aveparvovirus, Bocaparvovirus, Dependoparvovirus, Erythroparvovirus, Protoparvovirus, and Tetraparvovirus, respectively. Parvoviruses have a small linear single stranded DNA genome of $5 \mathrm{~kb}$ in length and a non-enveloped capsid with icosahedral symmetry (Tijssen et al. 2011). Unlike other parvoviruses, members of genus Bocaparvovirus (bocaparvoviruses) have an additional third open reading frame (ORF) named NP1, which is located between the first ORF

\footnotetext{
*Correspondence: lyoo@konkuk.ac.kr

1 Department of Pathology, College of Veterinary Medicine, Konkuk University, 120 Neung-dong Street, Gwangjin-gu, Seoul 143-701, South Korea

Full list of author information is available at the end of the article
}

coding nonstructural protein (NS1) and the second ORF that encodes structural proteins (VP1 and VP2) (Tijssen et al. 2011).

The first Porcine bocavirus (PBoV) known as a porcine boca-like virus was detected in the lymph node of Swedish pigs with post-weaning multi-systemic wasting syndrome (PMWS). Thereafter, several different strains of $\mathrm{PBoV}$ have been detected in respiratory tract secretions, fecal, serum, and urine samples of pigs from various countries (Lau et al. 2011; Zeng et al. 2011; Cheng et al. 2010; Blomstrom et al. 2009). According to 2013 ICTV species classification criterion, which stated that the identity of NS1 amino acid (aa) sequences should be under $85 \%$ in order to be demarcated as different species, PBoVs were classified into four species (Ungulate bocaparvovirus 2-5) (Cotmore et al. 2013).

In this study, we identified a novel porcine bocavirus (PBoV-KU14) in domestic pigs with respiratory problems, which has the shortest NP1 gene among all

\section{至 Springer}

(c) 2015 Yoo et al. This article is distributed under the terms of the Creative Commons Attribution 4.0 International License (http:// creativecommons.org/licenses/by/4.0/), which permits unrestricted use, distribution, and reproduction in any medium, provided you give appropriate credit to the original author(s) and the source, provide a link to the Creative Commons license, and indicate if changes were made. 
reported porcine bocaviruses. A phylogenetic and comparative analysis of PBoV-KU14 with other bocaparvoviruses indicated a possibility of crossover recombination. We also report conserved protein domains found in bocaparvoviruses.

One hundred and twenty-three serum samples from domestic pigs with respiratory problems or diarrhea in South Korea in 2012 were used to survey PBoV prevalence. Two degenerate primers (PBoV_F, PBoV_R), targeting the end of the NP1 gene and the beginning of the VP1/2 gene, were designed (Table 1 ) in order to classify viruses as either Ungulate bocaparvovirus (UB) 3/4 or Ungulate bocaparvovirus (UB) 2/5 species based on the size of DNA products. The expected PCR product size of $U B 2 / 5$ is $\sim 900 \mathrm{bp}$ and that of $U B 3 / 4$ is $\sim 720 \mathrm{bp}$, respectively.

The amplified DNA was run on a $1.2 \%$ agarose gel and the appropriate DNA band (720 or $900 \mathrm{bp}$, as mentioned above) was extracted using QIAquick Gel Extraction kit (QIAGEN) and subjected to sequence analysis (Macrogen, Korea). While twenty (16.3\%) and fourteen samples (11.4\%) showed a single positive band of 720 and $900 \mathrm{bp}$, respectively, three serum samples $(2.4 \%)$ showed double bands (900 and $720 \mathrm{bp}$ ) indicating co-infection between the viruses of $U B 3 / 4$ and $U B 2 / 5$.

Among 23 samples of $720 \mathrm{bp}$ amplified PCR product, three sequences from each of three weaning pigs with

Table 1 Ten sets of primers used to obtain nearly complete genome sequence of PBoV-KU14

\begin{tabular}{|c|c|}
\hline Primer name & Sequence $\left(5^{\prime}-3^{\prime}\right)$ \\
\hline \multirow[t]{2}{*}{ PBoV } & F: KCACTTYAGATTTACTSMDTGT \\
\hline & R:TTBAVDARYCWYTGCCAKTC \\
\hline \multirow[t]{2}{*}{ PBoV1 } & F:TGCTAAAAGGGCTAGAATG \\
\hline & R: CCYGTBVMGTADATRTTBAG \\
\hline \multirow[t]{2}{*}{ PBoV2 } & F: GCGCAAATTCATCAGAACCA \\
\hline & R: KHCCMMAYYKNGTTGGCATG \\
\hline \multirow[t]{2}{*}{ PBoV3 } & F:TGACCTAACCAGGTGGGGAA \\
\hline & R: MVMWMWSMADWWDDSYKKBHT \\
\hline \multirow[t]{2}{*}{ PBoV4 } & F: GGDCCHGCCAGYACRGGNAA \\
\hline & R:TGGTTGTGATGCCCACTTGT \\
\hline \multirow[t]{2}{*}{ PBoV5 } & F: GATCCGCTTTCTGATCTGCC \\
\hline & R: ATTCTCACGGTTGTTCCTCCC \\
\hline \multirow[t]{2}{*}{ PBov6 } & F: GTTTGGGGGATAGCGAGCAT \\
\hline & R: CCTCCCGGCTGAGTTGTTTTT \\
\hline \multirow[t]{2}{*}{ PBoV7 } & F: ATGTTTGGGGGATAGCGAGC \\
\hline & R: AGGCAGATCAGAAAGCGGAT \\
\hline \multirow[t]{2}{*}{ PBoV8 } & F: GGAMRWAADDMTYRDWWWAAYAG \\
\hline & R:TTTTGTGAGTCCGTCTCCTG \\
\hline \multirow[t]{2}{*}{ PBoV9 } & F: GTNTGGTGGGAAGAAGCRYTGA \\
\hline & R: GCTGCCGTGTTCTTTGGATTT \\
\hline
\end{tabular}

respiratory problems in one pig farm had $72 \%$ maximum identity with prototype PBoV-H18 (HQ291308), and identity between these three sequences was $99-100 \%$. One of the three samples was selected to obtain the full genome sequence and unknown $5^{\prime}$ - and $3^{\prime}$-end sequences were obtained using a primer walking method (Kapoor et al. 2010) with nine sets of primers (Table 1). Each PCR amplicon for ten primer sets was sequenced in triplicate and assembled using Bioedit v7.2.5. A total of 4,630 bp without terminal sequences was obtained and submitted to GeneBank (accession number KJ622366). The remained two samples were used for the comparison of NP1 gene with that of PBoV-KU14 in aspect of length and nucleotide composition, which resulted in the same length and $99-100 \%$ identity.

The base composition of PBoV-KU14 was A (37.5\%), C (19.0\%), G (21.3\%) and T (22.2\%). Three open reading frames were identified using ORF finder (Rombel et al. 2002). The ORFs (NS1, NP1, VP1/2) of PBoV-KU14 comprised 1,908 bp (1-1,908 bp), $600 \mathrm{bp}(2,136-2,735 \mathrm{bp})$, $1,851 \mathrm{bp}(2,780-4,630 \mathrm{bp})$, respectively.

Phylogenetic analysis was performed using the molecular evolutionary genetics analysis (MEGA) v6 software in neighbor-joining (NJ) method mode with 1,000 bootstrap replicates. First of all, to identify relationships between PBoV-KU14 and other viruses belonging to the subfamily Parvovirinae, we performed phylogenetic analysis of the almost full-length nucleotide sequences, including from the start of the NS1 gene to the end of VP1/2. A total of 53 nearly complete genome sequences representing different parvovirus species of the subfamily Parvovirinae were used in this analysis. The results indicated that PBoV-KU14 was classified in the genus Bocaparvovirus (Figure 1). Additionally, phylogenetic trees based on the amino acid sequences of NS1, NP1, VP1/2 protein were also constructed to survey genetic distances between all known PBoVs (Figure 2).

According to the ICTV criteria (Cotmore et al. 2013), PBoV-KU14 was identified as a new strain of $U B 4$ species (Figure 2a), showing amino acid identity of $94.9,76.1 \%$ with PBoV-H18, SX, respectively. However, incongruent clustering was detected between the phylogenetic trees based on NS1, NP1 and VP1/2 proteins of PBoVs of $U B 3$ or UB4. The phylogenic incongruence was noticeable, especially in the classification of PBoV-KU14 (Figure 2), which highlights potential drawbacks with the current species classification system of ICTV. Amino acid identity of NP1 of PBoV-KU14 with those of PBoV-H18 and PBoV-SX was 58.1 and $58.9 \%$, respectively; the identity of the VP1/2 proteins was 76.4 and $75.5 \%$, respectively.

Comparative analysis of PBoV-KU14 with members of genus Bocaparvovirus was performed using tools for partial alignment (BLAST) (McGinnis and Madden 2004) 


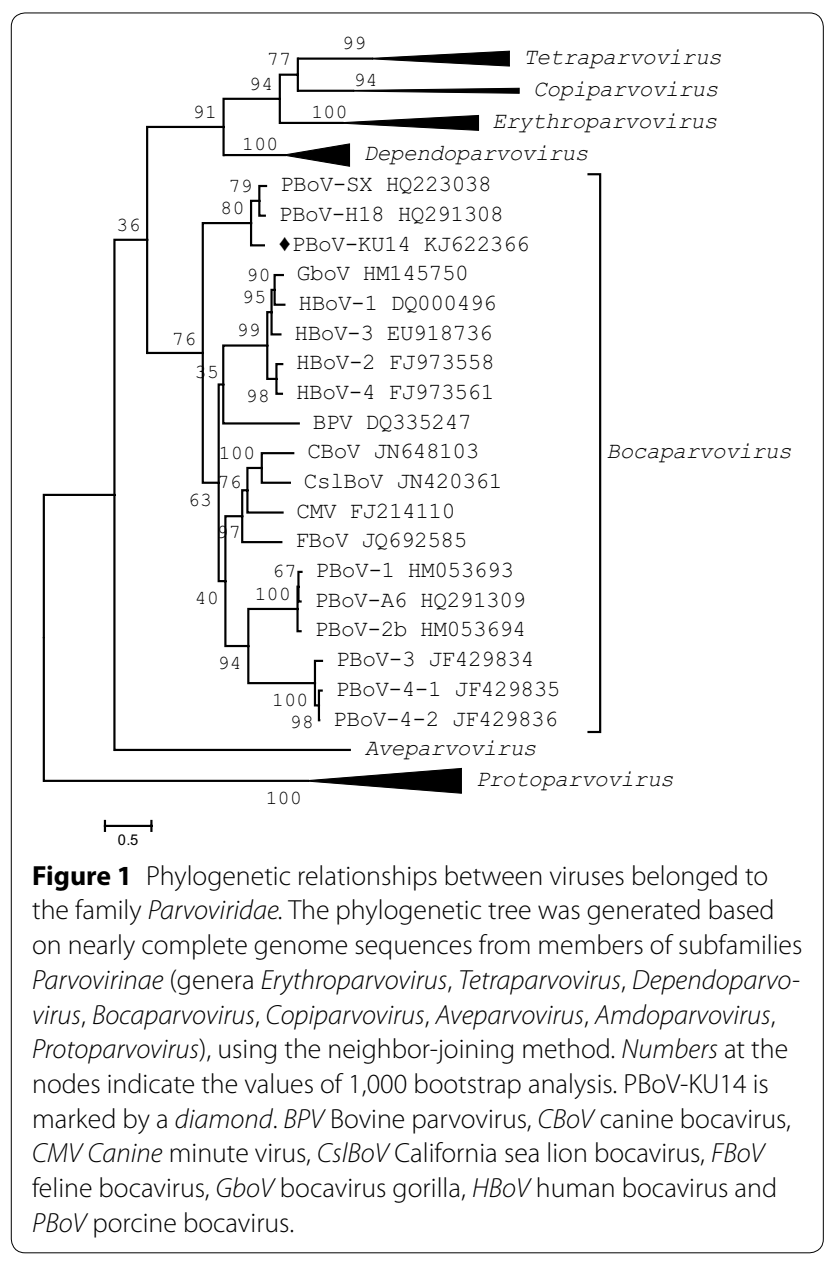

and multiple alignment (ClustalW) (Thompson et al. 2002) with motif based sequence analysis tools (MEME suite) (Bailey et al. 2009). Partial alignment at the nucleotide level under $e$-value cutoff $\leq 10^{-6}$ revealed that nucleotides (nt) 1,909-2,049, 2,127-2,348, and 2,721-2,932 of PBoV-KU14 genome did not share any consensus sequence, which implies that these regions are not highly conserved. These domains include the $5^{\prime}$ terminal region of the NP1 (2,136-2,348 bp, 1-71 aa) and VP1 unique region (VP1u, 2,780-2,932 bp, 1-51aa). Otherwise, other regions of the PBoV-KU14 genome showed high identity with viruses of the $U B 3$ or 4 .

Multiple alignment with protein motif analysis revealed that the region corresponding to 91-188 aa $(2,406-$ 2,699 bp) of the NP1 protein of PBoV-KU14 is highly conserved in the genus Bocaparvovirus and the VP1u protein of all bocaparvoviruses possesses a putative conserved C-terminal motif (Figure 3). Even though the protein functions of the conserved regions were not predictable due to insufficient online database of protein function,

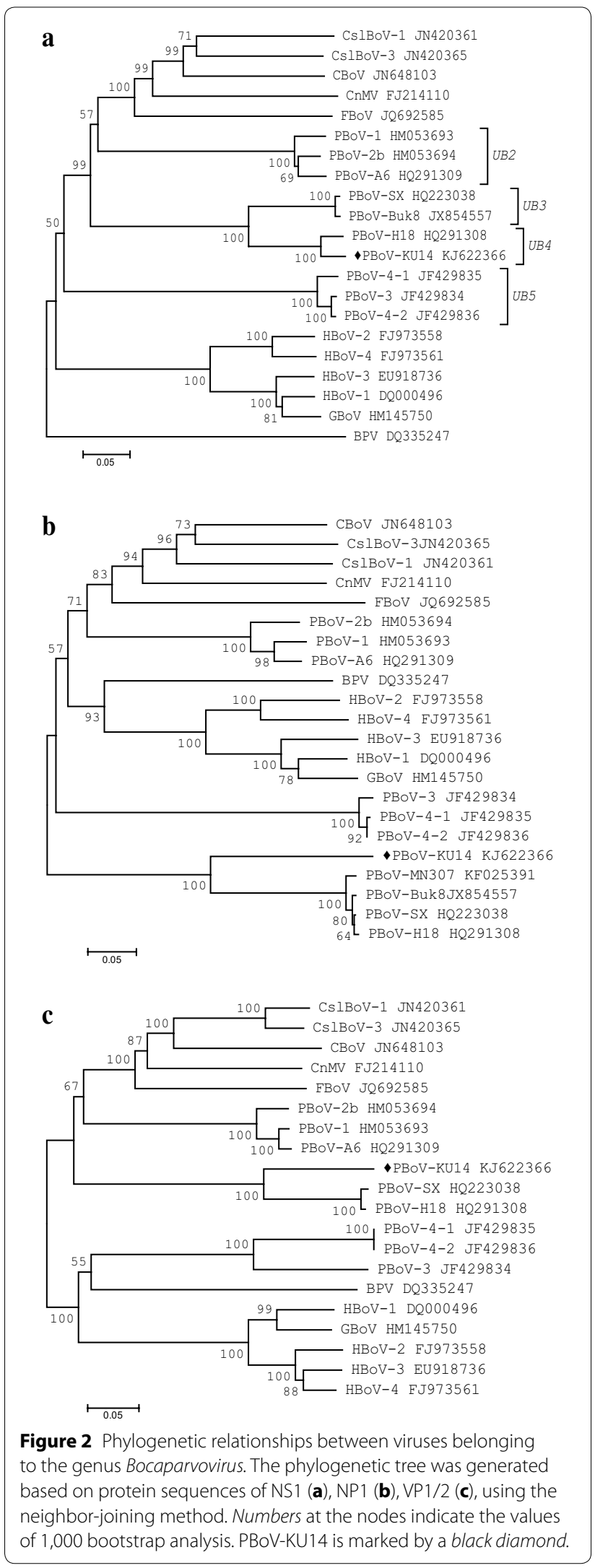




\section{$\mathbf{a}$ \\ CnMV FJ214110 \\ CBOV JN648103 \\ FBOV Jo692585 \\ CslBoV-1 JN420361 \\ CslBoV-3 JN420365 \\ HBOV-1 DQ000496 \\ HBOV-2 FJ973558 \\ HBOV-3 EU918736 \\ HBOV-4 FJ973561 \\ GBoV HM1 45750 \\ BPV DQ 335247 \\ PBOV-1 HM053693 \\ PBOV-2b HM053694 \\ PBOV-A6 HQ291309 \\ PBOV-SX HQ223038 \\ PBOV-Buk8 JX854557 \\ PBOV-H18 HO291308
PBOV-MN307 KF025391 \\ PBOV-KU14 KJ622366 \\ PBOV-3 JF429834 \\ PBOV-4-1 JF429835 \\ PBOV-4-2 JF429836}

\section{b}

CnMV FJ214110

CBOV JN64810

FBOV JQ692585

CslBoV-1 JN420361

CSIBOV-3 JN42036

HBOV-1 DO000496

HBOV-2 FJ973558

HBOV-3 EU918736

HBOV-4 FJ973561

GBOV HM1 45750

BPV DQ335247

PBOV-1 HM0 53693

PBOV-2b HM053694

PBoV-A6 HQ291309

PBoV-SX HQ223038

PBOV-H18 HQ291308

PBOV-KU14 KJ62236

PBOV-3 JF429834

PBOV-4-1 JF429835

PBoV-4-2 JF42983

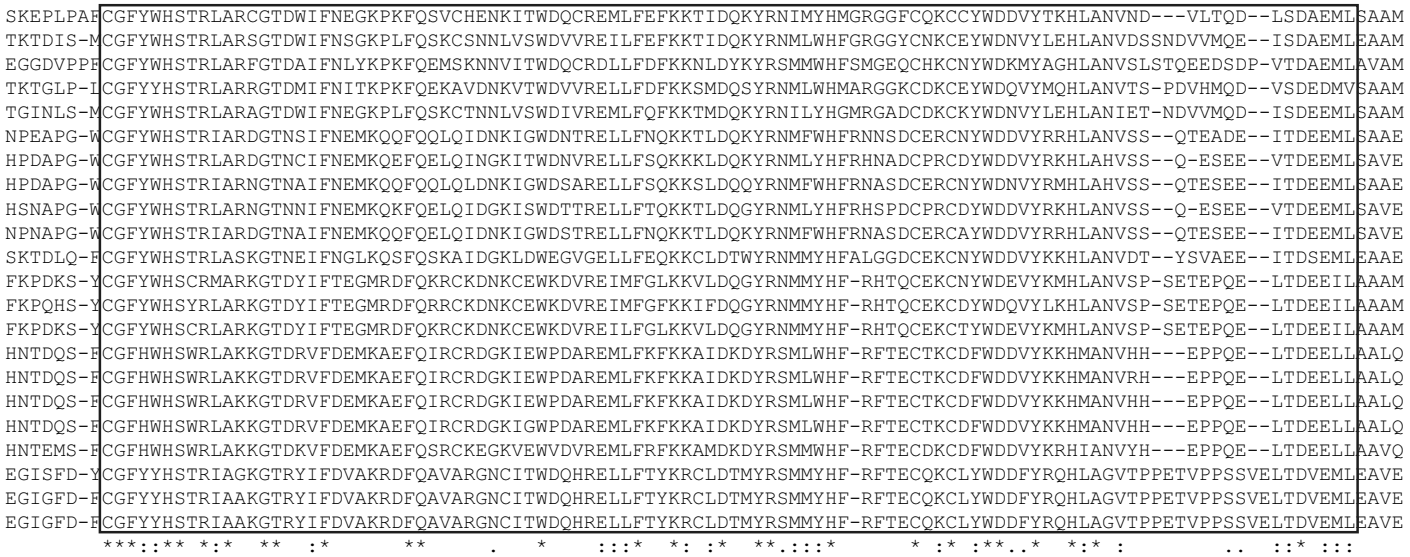

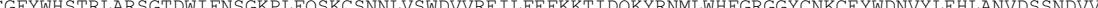
作 TKTGLP-I CGFYYHSTRLARRGT DMIFNITKPKFQEKAVDNKVTWDVVRELLF DFKKSMDQSYRNMLWHMARGGKCDKCEYWDQVYMQHLANVTS-PDVHMQD--VSDEDMV NPEAPG-WCG HPDAPG-WCGFYWHSTRLARDGTNCI FNEMKOEFOELOINGKITWDNVRELLFSOKKKLDOKYRNMLYHFRHNADCPRCDYWDDVYRKHLAHVSS--O-ESEE--VTDEEML

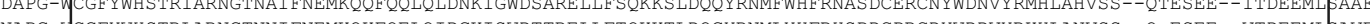
SKTDIQFKPDKS - Y CGFYWHSCRMARKGTDY I FTEGMRDFOKRCKDNKCEWKDVRE IMFGLKKVLDQGYRNMMYHF-RHTQCEKCNYWDEVYKMHLANVSP-SETEPQE--LTDEE I L AAAM FKPQHS-Y CGFYWHSYRLARKGTDY IFTEGMRDFQRRCKDNKCEWKDVRE IMFGFKKI FDQGYRNMMYHF-RHTQCEKCDYWDQVYLKHLANVSP-SETEPQE--LTDEEILAAAM FKPDKS-YCGFYWHSCRLARKGTDY IFTEGMRDFQKRCKDNKCEWKDVRE I LFGLKKVLDQGYRNMMYHF-RHTQCEKCTYWDEVYKMHLANVSP-SETEPQE--LTDEE I LAAAM HNTDQS-HCGFHWHSWRLAKKGTDRVFDEMKAEFQIRCRDGKIEWPDAREMLFKFKKAIDKDYRSMLWHF-RFTECTKCDFWDDVYKKHMANVHH---EPPQE--LTDEE LLAALQ HNTDOS-HCGFHWHSWRLAKKGTDRVFDEMKAEFOIRCRDGKIEWPDAREMLFKFKKAIDKDYRSMLWHF-RFTECTKCDFWDDVYKKHMANVRH---EPPOE--LTDEELLAALO DQS-HCGFHWHSWRLAKKGTDRVFDEMKAEFQIRCRDGKIEWPDAREMLFKFKKAIDKDYRSMLWHF-RFTECTKCDFWDDVYKKHMANVHH---EPPQE--LTDEELIAALQ DQS-ACFHWHSWRLAKKGTDRVFDEMKAEFQIRCRDGKIGWPDAREMLFKFKKAIDKDYRSMLWHF-RFTECTKCDFWDDVYKKHMANVHH---EPPQE--LTDEELIAALQ EGISFD-Y CGFYYHSTRIAGKGTRY I FDVAKRDFQAVARGNCITWDQHRELLFTYKRCLDTMYRSMMYHF-RFTECQKCLYWDDFYRQHLAGVTPPETVPPSSVELTDVEMLEAVE EGIGED-ACGFYYHSTRIAAKGTRY IFDVAKRDFQAVARGNCI TWDQHRELLFTYKRCLDTMYRSMMYHF-RFTECQKCLYWDDFYRQHLAGVTPPETVPPSSVELTDVEMLEAVE

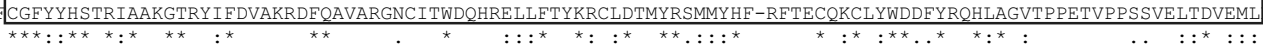

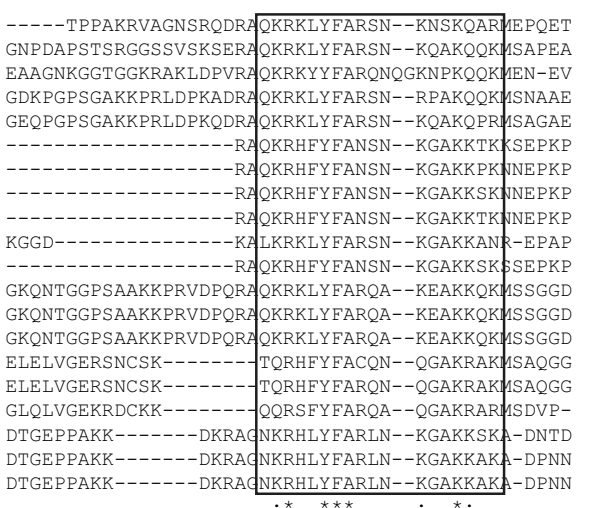

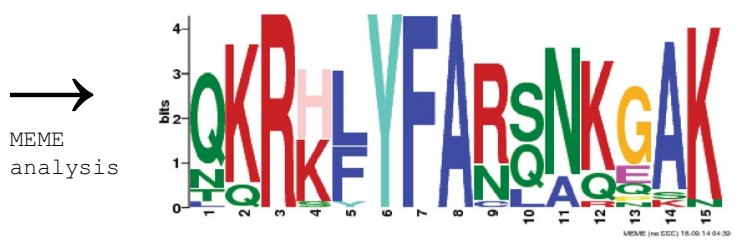

Figure 3 Conserved domain in NP1 protein (a) and expected protein motif in VP1 u protein (b).

these findings provide additional insight into the general functions of the bocaparvovirus NP1 and VP1u protein.

The length of each protein encoded by NS1, NP1, and VP1/2 ORFs are longest in viruses of the UB2 strain and shortest in $U B 3$ and 4 viruses. While the length of NP1 protein is 218 aa in both $U B 3$ and $U B 4$, the corresponding protein is 226 and $228-230$ aa long in $U B 5$ and $U B 2$, respectively (Table 2). Even though PBoV-KU14 belongs to the UB4 strain, it expresses an NP1 protein that is 199 aa long. Through comparative analysis, the truncation could be attributed to the shorter $5^{\prime}$ terminal region of the NP1 gene $(2,136-2,348 \mathrm{bp}, 1-71 \mathrm{aa})$, which is an area of low conservation, than that of other members of the $U B 3$ and 4. This shortening is due to two events. First, there has been a substitution at the start codon of the NP1 gene. In PBoV-KU14, the start codon of NP1 gene is replaced by $\mathrm{ACA}$, with a consequent shift in translation
Table 2 Comparison of the length of three encoded proteins (NS1, NP1 and VP1 u/2) among different PBoV species

\begin{tabular}{lllll}
\hline Species & Strain (accession number) $^{\text {a }}$ & \multicolumn{3}{l}{ The length of } \\
\cline { 3 - 5 } & & NS1 & NP1 & VP1 u/VP2 \\
\hline UB2 & PBoV-1 (HM053693) & 703aa & 228aa & 137/705aa \\
& PBoV-2b (HM053694) & 703aa & 230aa & 137/709aa \\
& PBoV-A6 (HQ291309) & 703aa & 228aa & 137/704aa \\
UB3 & PBoV-SX (HQ223038) & 636aa & 218aa & 68/623aa \\
& PBoV-Buk8 (JX854557) & 637aa & 218aa & NA \\
UB4 & PBoV-H18 (HQ291308) & 635aa & 218aa & 68/620aa \\
& PBoV-KU14 (KJ622366) & 635aa & 199aa & 67/618aa \\
UB5 & PBoV-3 (JF429834) & 667aa & 226aa & 135/683aa \\
& PBoV-4-1 (JF429835) & 667aa & 226aa & 135/683aa \\
& PBoV-4-2 (JF429836) & 667aa & 226aa & 135/683aa
\end{tabular}

NA not available, PBoV porcine bocavirus and UB Ungulate bocaparvovirus.

a Strain found in this study was written in italics letter. 


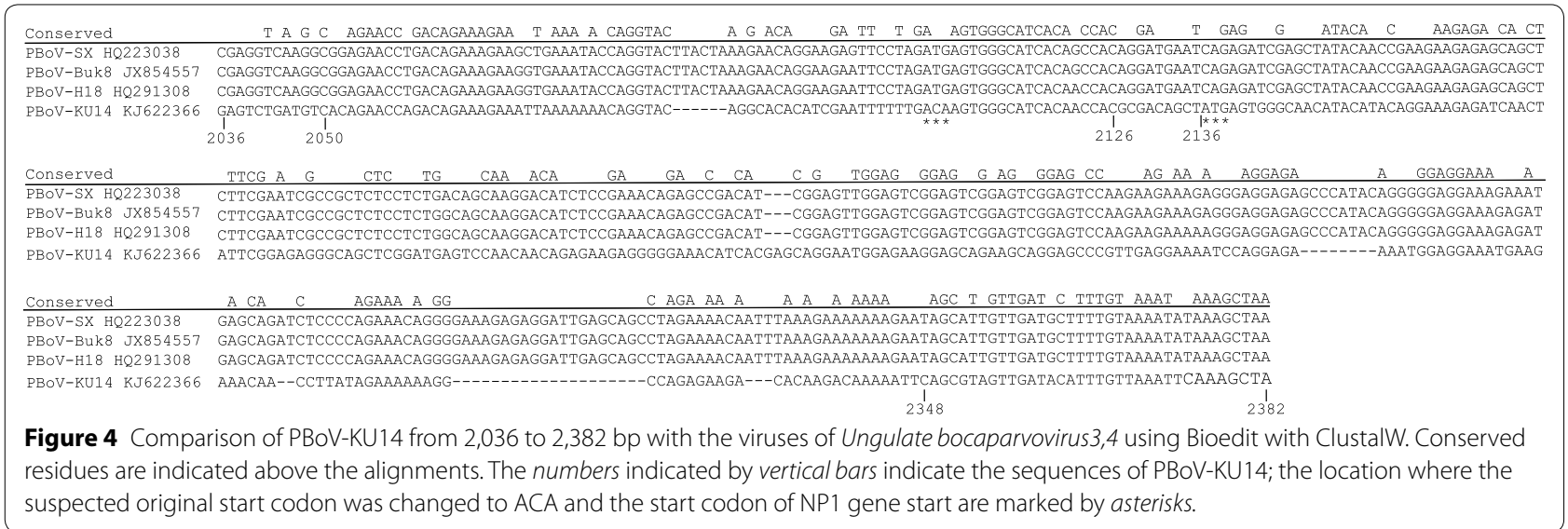

initiation to a site $30 \mathrm{nt}$ downstream of the original ATG. Second, a discontinuous deletion was detected in the $5^{\prime}$ terminal NP1 gene, which caused the NP1 protein of PBoV-KU14 to be 9 aa shorter (Figure 4). We presume that the 57 nt (i.e., 19 aa) truncation occurred on the basis of the two events mentioned above, and explain the changes to the length of NP1 protein.

Viruses may achieve genetic diversity and adaptation through point mutation and recombination. Recombination leads to more rapid and massive viral evolution than point mutations, and results in either quasispecies or defective genomes. Previous reports of phylogenetic discord were attributed to recombination in parvoviruses (Yang et al. 2012; Ohshima and Mochizuki 2009; Kapoor et al. 2010; Tyumentsev et al. 2014) including the viruses of UB5 (Xiao et al. 2013). Similar to other parvoviruses, through the results of phylogenetic and comparative analysis, we presume that the crossover recombination occurred before the region of the conserved NP1 gene during the speciation process. The truncation of the 5 terminal region of NP1 gene also seemed to be associated with recombination. Gene truncation is a phenomenon considered as host adaption that is found not only in pathogenic field strains of virus in in vitro cell culture systems (Pan et al. 2012; Steel et al. 2009) but also in naturally occurring viruses, such as the highly pathogenic porcine reproductive and respiratory syndrome virus ( $\mathrm{Yu}$ et al. 2012). To determine whether this truncation is the result of viral adaptation to the host or is an independent event resulting from close contact between domestic pigs, periodic prevalence survey of PBoV-KU14 and studies of recombination occurring in $\mathrm{PBoVs}$ will be required. Additionally, because PBoVs have high intrinsic substitution rates (Babkin et al. 2013), and the chance that different PBoVs co-exist in one host is high, genetic change of PBoVs should be monitored carefully, and new strains should be subjected to persistent surveillance.

\section{Authors' contributions}

YSL, SJY participated in the design of this study. SSK, SHJ and DUL contributed to the sampling and analysis. YSL and SJY contributed to the interpretation of data and drafting the manuscript. SYS contributed to ciritical revision of the paper. All authors read and approved the final manucript.

\section{Author details}

1 Department of Pathology, College of Veterinary Medicine, Konkuk University, 120 Neung-dong Street, Gwangjin-gu, Seoul 143-701, South Korea. ${ }^{2}$ Present Address: Department of Diagnostic Medicine/Pathobiology, College of Veterinary Medicine, Kansas State University, Manhattan, KS 66506, USA.

Compliance with ethical guidelines

\section{Competing interests}

The authors declare that they have no competing interests.

Received: 1 April 2015 Accepted: 10 July 2015

Published online: 24 July 2015

\section{References}

Babkin IV, Tyumentsev Al, Tikunov AY, Kurilshikov AM, Ryabchikova El, Zhirakovskaya EV et al (2013) Evolutionary time-scale of primate bocaviruses. Infect Genet Evol Journal Mol Epidemiol Evol Genet Infect Dis 14:265-274 Bailey TL, Boden M, Buske FA, Frith M, Grant CE, Clementi L et al (2009) MEME SUITE: tools for motif discovery and searching. Nucleic Acids Res 37(Web Server issue):W202-W208

Blomstrom AL, Belak S, Fossum C, McKillen J, Allan G, Wallgren P et al (2009) Detection of a novel porcine boca-like virus in the background of porcine circovirus type 2 induced postweaning multisystemic wasting syndrome. Virus Res 146(1-2):125-129

Cheng WX, Li JS, Huang CP, Yao DP, Liu N, Cui SX (2010) Identification and nearly full-length genome characterization of novel porcine bocaviruses. PLoS One 5(10):e13583. doi:10.1371/journal.pone.0013583

Cotmore SF, McKenna MA, Chiorini JA, Gatherer D, Mukha DV, Pintel DJ et al. (2013) Rationalization and extension of the taxonomy of the family Parvoviridae. In: Offical Taxonomy Proposals. International Committee on Taxonomy of Viruses Online database. Available via ICTV Home. http:// www.talk.ictvonline.org/media/22/default.aspx/. Accessed 26 Mar 2014

Kapoor A, Simmonds P, Slikas E, Li L, Bodhidatta L, Sethabutr O et al (2010) Human bocaviruses are highly diverse, dispersed, recombination prone, and prevalent in enteric infections. J Infect Dis 201(11):1633-1643

Lau SK, Woo PC, Yip CC, Li KS, Fu CT, Huang Y et al (2011) Co-existence of multiple strains of two novel porcine bocaviruses in the same pig, a previously undescribed phenomenon in members of the family Parvoviridae, and evidence for inter- and intra-host genetic diversity and recombination. J Gener Virol 92(Pt 9):2047-2059 
McGinnis S, Madden TL (2004) BLAST: at the core of a powerful and diverse set of sequence analysis tools. Nucleic Acids Res 32(Web Server issue):W20-W25

Ohshima T, Mochizuki M (2009) Evidence for recombination between feline panleukopenia virus and canine parvovirus type 2. J Vet Med Sci Jpn Soc Vet Sci 71(4):403-408

Pan Y, Tian X, Li W, Zhou Q, Wang D, Bi Y et al (2012) Isolation and characterization of a variant porcine epidemic diarrhea virus in China. Virol J 9:195

Rombel IT, Sykes KF, Rayner S, Johnston SA (2002) ORF-FINDER: a vector for high-throughput gene identification. Gene 282(1-2):33-41

Steel J, Lowen AC, Pena L, Angel M, Solorzano A, Albrecht R et al (2009) Live attenuated influenza viruses containing NS1 truncations as vaccine candidates against H5N1 highly pathogenic avian influenza. J Virol 83(4):1742-1753

Thompson JD, Gibson TJ, Higgins DG (2002) Multiple sequence alignment using ClustalW and ClustalX. In: Andreas D Baxevanis et al. Current protocols in bioinformatics, 00:02.03:02.03.01-02.03.22

Tijssen P, Agbandje-McKenna M, Almendral JM, Bergoin M, Flegel TW, Hedman Ket al (2011) Family Parvoviridae. In: King AMQ, Adams MJ, Carstens EB, Lefkowitz EJ (eds) Virus taxonomy; 9th report of the International Committee on taxonomy of viruses. Elsevier Academic Press, London, pp 405-425
Tyumentsev Al, Tikunova NV, Tikunov AY, Babkin IV (2014) Recombination in the evolution of human bocavirus. Infect Genet Evol Journal Mol Epidemiol Evol Genet Infect Dis 28:11-14

Xiao CT, Halbur PG, Opriessnig T (2013) Molecular evolutionary genetic analysis of emerging parvoviruses identified in pigs. Infect Genet Evol Journal Mol Epidemiol Evol Genet Infect Dis 16:369-376

Yang WZ, Yu JM, Li JS, Cheng WX, Huang CP, Duan ZJ (2012) Genome characterization of a novel porcine bocavirus. Arch Virol 157(11):2125-2132

Yu X, Chen N, Wang L, Wu J, Zhou Z, Ni J et al (2012) New genomic characteristics of highly pathogenic porcine reproductive and respiratory syndrome viruses do not lead to significant changes in pathogenicity. Vet Microbiol 158(3-4):291-299

Zeng S, Wang D, Fang L, Ma J, Song T, Zhang R et al (2011) Complete coding sequences and phylogenetic analysis of porcine bocavirus. J Gen Vir 92(Pt 4):784-788

\section{Submit your manuscript to a SpringerOpen ${ }^{\circ}$ journal and benefit from:}

- Convenient online submission

- Rigorous peer review

- Immediate publication on acceptance

- Open access: articles freely available online

- High visibility within the field

- Retaining the copyright to your article

Submit your next manuscript at $>$ springeropen.com 